\title{
Opposing time trends of peptic ulcer and reflux disease
}

H B El-Serag, A Sonnenberg

\begin{abstract}
Background-Gastritis associated hypochlorhydria may be protective against gastro-oesophageal reflux disease. It was hypothesised that the historic decline in Helicobacter pylori infection resulted in a decline in peptic ulcer and a concomitant rise in reflux disease.

Aims-To study the time trends of peptic ulcer and reflux disease.

Methods-Hospitalisation rates were analysed using the computerised database of the US Department of Veterans Affairs from 1970 until 1995. Death rates were calculated from the Vital Statistics of the United States.

Results-From 1970 to 1995 , hospitalisation rates for gastric and duodenal ulcer, as well as gastric cancer fell, while the hospitalisation rates for gastro-oesophageal reflux disease and those for oesophageal adenocarcinoma rose significantly. Similar time trends were observed with respect to the death rates. There were notable ethnic differences. White subjects incurred higher rates of reflux disease and oesophageal adenocarcinoma and lower rates of gastric ulcer or cancer compared with non-whites.

Conclusions-The ethnic variations and the opposing time trends of gastroduodenal versus oesophageal disease are consistent with the hypothesis that the declining infection rates of $H$ pylori in the general population have led to $a$ rise in the occurrence of gastro-oesophageal reflux disease and associated oesophageal adenocarcinoma.

(Gut 1998;43:327-333)
\end{abstract}

Keywords: gastric cancer; gastritis; gastro-oesophageal reflux disease; hypochlorhydria; Helicobacter pylori: oesophageal adenocarcinoma

Department of Veterans Affairs Medical Center and University of New Mexico, Albuquerque, New Mexico, USA

H B El-Serag

A Sonnenberg

Correspondence to: Dr A Sonnenberg, Gastroenterology Section, Department of Veterans Affairs Medical Center 111F 2100 Ridgecrest Drive SE, Albuquerque, New Mexico 87108, USA.

Accepted for publication 26 March 1998 associated with a chronic Helicobacter pylori infection of the gastroduodenal mucosa. ${ }^{3-5}$ The time trends of $H$ pylori in developed countries have been notable by a decrease in the infection rate. ${ }^{67}$ It appears likely that the observed decline in the occurrence of both ulcer types and gastric cancer stemmed from an underlying decline in the infection rates with $H$ pylori. The development of corpus gastritis secondary to a chronic $H$ pylori infection reduces gastric secretion of acid. ${ }^{8}$ This process appears to be partially reversible, as eradication of $H$ pylor $i$ in order to cure peptic ulcer disease can result in new onset of gastro-oesophageal reflux disease (GORD). ${ }^{11}{ }^{11}$ Furthermore, patients with an endoscopically diagnosed reflux oesophagitis are less likely to harbour active corpus gastritis than patients without oesophagitis. ${ }^{12}$ We hypothesised that the recent decline in the $H$ pylori infection rates of the general population resulted not only in a fall in peptic ulcer and gastric cancer, but also in a concomitant rise in reflux disease. To test this hypothesis, we analysed the time trends of mortality and hospitalisation secondary to gastric ulcer, duodenal ulcer, and gastric cancer and compared them with similar time trends secondary to GORD and oesophageal adenocarcinoma.

\section{Methods}

DATA SOURCES

Two large and independent databases were used to analyse hospitalisation and mortality data in the United States. Hospitalisation was studied using the computerised database of the Department of Veterans Affairs (VA) - that is, the Patient Treatment File (PTF). The data files contained the records of all inpatients from all 172 VA hospitals distributed throughout the United States. The PTF is managed by the VA Central Automation Center in Austin, Texas. It was started in 1970, and files were available for each year until 1995. Each annual file contained the records of about one million hospitalisations. In addition to demographic characteristics, each patient record contained one primary and up to four secondary discharge diagnoses. In 1984, the number of potential secondary diagnoses was increased to nine. From 1970 to 1980 , the discharge diagnoses were encoded according to the eighth revision of the International Classification of Diseases Adapted for Use in the United States (ICDA8). ${ }^{13}$ Since 1981, the ninth revision of the Clinical Modification of the International Classification of Diseases was used (ICD9-CM). ${ }^{14}$ Data were extracted by age and ethnicity, but not by sex, since over $98 \%$ of all hospitalised veterans were men.

To confirm the trends observed with respect to hospitalisation, we compared them with similar data obtained from the Vital Statistics of the United States. The mortality data had 
been accumulated yearly by the National Center for Health Statistics (NCHS). Each annual data set was compiled from microfilm copies of all 1.9 to 2 million death certificates in the United States (with the exception of 1972, which contained a 50\% sample only). The data were available through annual publications of the NCHS. ${ }^{15}$ The data from 1979 until 1992 could also be retrieved through the home page of the Center for Disease Control on the internet (http://www.wonder.cdc.gov/). The information contained in the publications or on the internet included age, race, sex, and underlying cause of death for each decedent. From 1968 to 1978 , the causes of death were encoded by the NCHS according to ICD8 and since 1979 according to ICD9.

\section{DIAGNOSTIC CODES}

For every year from 1970 to 1995 , the following five broad categories of hospital discharge diagnoses were extracted from the PTF: cancer of the gastric corpus and antrum; oesophageal adenocarcinoma and cancer of cardia; gastric ulcer; duodenal ulcer; and GORD. In case of gastric cancer all four digit variants were used, except code 151.0. The ICDA8 code 151.0 was assigned to cancers of the cardia and cardiac orifice. The corresponding ICD9-CM code 151.0 for the cardia and the cardiac orifice contains the additional stipulation to use this code especially for oesophageal adenocarcinoma. This stipulation is not contained in the ICD9. It is important to keep in mind that the vital statistics, cancer registries in the US, and other non-US data sets might differ in this particular aspect from the ICDA8 and ICD9-CM. In both types of peptic ulcer, all four and five digit variants of their coding were included to cover all forms of ulcer disease. GORD was comprised of four distinct codes: erosive oesophagitis (530.1), oesophageal ulcers (530.2), oesophageal strictures (530.3), and hiatus hernia (553.3). To ensure that only cases with GORD related diagnoses were considered, patients with any discharge diagnosis of infectious, radiation induced, or caustic oesophagitis were excluded from the case population. The same diagnoses were extracted from the Vital Statistics with the exception of GORD. In the mortality data, coding for erosive oesophagitis became consistent and relatively frequent only in 1979 . Therefore, the analysis of GORD in the Vital Statistics was confined to erosive oesophagitis from 1979 until 1992.
STATISTICAL ANALYSIS

For each year and diagnostic category, the numbers of hospital discharges were broken down by race and 10 year age groups. Similarly, the total numbers of hospital discharges for all diagnoses were broken down by race and age. The race and age specific discharges of each five consecutive years were added up, for instance, from 1970 to 1974 , from 1975 to 1979 , etc. To calculate proportional hospitalisation rates, the number of hospitalisations for a particular diagnosis was divided by the total number all hospitalisations during the same five year period. Subsequently, these race and age specific rates were adjusted by the method of direct standardisation to the age distribution of all hospitalised veterans in $1990 .{ }^{16}$ The average age adjusted rates of consecutive five year time periods were then expressed as proportional rates per 10000 hospitalisations. The data were plotted separately for whites and non-whites.

The death rates were calculated similarly with three noteworthy exceptions. Firstly, the five year time periods were chosen as follows: 1968-1972, 1973-1977, etc. Secondly, the aggregate US population of each consecutive five years was used as denominator to calculate death rates per 1 million living population. Finally, the data were plotted broken down by sex, as well as race.

As the Patient Treatment File and the Vital Statistics cover the entirety of two populations-that is, the veterans population and the US population, calculation of common statistical parameters such as standard error or standard deviation is not feasible. To be able to estimate the strength and validity of the observed patterns, we assumed that hospitalisation discharges and deaths behave like Poisson variables. The $95 \%$ confidence interval of each rate was then calculated using the upper and lower estimate of each number of hospitalisations or deaths. ${ }^{17}$ Any two rates were considered significantly different, if their two confidence intervals did not overlap.

\section{Results}

Because of the large size of the population of hospitalised veterans, all diseases of interest appeared frequently as discharge diagnoses (table 1). By analysing the average rates of five year time periods, the time trends showed a relatively stable and consistent behaviour without major irregularities. Hospitalisation rates for cancer of the corpus and antrum decreased significantly between 1970 and 1995 in both

Table 1 Mean number of cases per year and population sizes

\begin{tabular}{llll}
\hline ICD9-CM codes & Diagnosis & $\begin{array}{l}\text { VA hospitalisation } \\
\text { statistics (1970-1995) }\end{array}$ & $\begin{array}{l}\text { US mortality } \\
\text { statistics (1968-1992) }\end{array}$ \\
\hline 151.0 & Oesophageal adenocarcinoma/cancer of cardia & 276 & 387 \\
$151.1-151.9$ & Cancer of corpus, antrum, and other stomach nos & 1492 & 14387 \\
$530.1-530.3,553.3$ & Gastro-oesophageal reflux diseaset & 16130 & 379 \\
$531.00-531.91$ & Gastric ulcer & 5234 & 2553 \\
$532.00-532.91$ & Duodenal ulcer & 7656 & 2684 \\
& Population & 942621 & 226169040 \\
\hline
\end{tabular}

$\star$ nos, not otherwise specified.

† Mortality data were restricted to oesophagitis (ICD code 530.1) from 1979 to 1992. 
Table 2 Proportional hospitalisation rates, veterans population 1970-1995

\begin{tabular}{llcccc}
\hline Subgroup & Gastric ulcer & Duodenal ulcer & Reflux oesophagitis & Gastric cancer & Cancer of the cardia \\
\hline Whites $^{\star}$ & $55.3(54.9-55.6)$ & $83.3(82.9-83.7)$ & $188.6(188.0-189.2)$ & $12.9(12.7-13.1)$ & $3.2(3.1-3.3)$ \\
Non-whites & $56.4(55.8-57.0)$ & $73.8(73.1-74.6)$ & $109.3(108.4-110.2)$ & $26.2(25.8-26.6)$ & $2.0(1.8-2.1)$ \\
$1970-1974$ & $67.6(66.9-68.3)$ & $168.8(167.7-170.0)$ & $61.2(60.5-61.9)$ & $22.1(21.7-22.6)$ & $1.3(1.2-1.4)$ \\
$1990-1995$ & $49.6(49.0-50.1)$ & $52.5(51.9-53.1)$ & $315.6(314.2-317.1)$ & $14.3(13.9-14.6)$ & $4.8(4.7-5.0)$ \\
\hline
\end{tabular}

Rates are expressed per 10000 hospitalisations from all causes and shown with their $95 \%$ confidence interval.

$\star$ Rates for whites and non-whites represent the average values of the period 1970-1995.
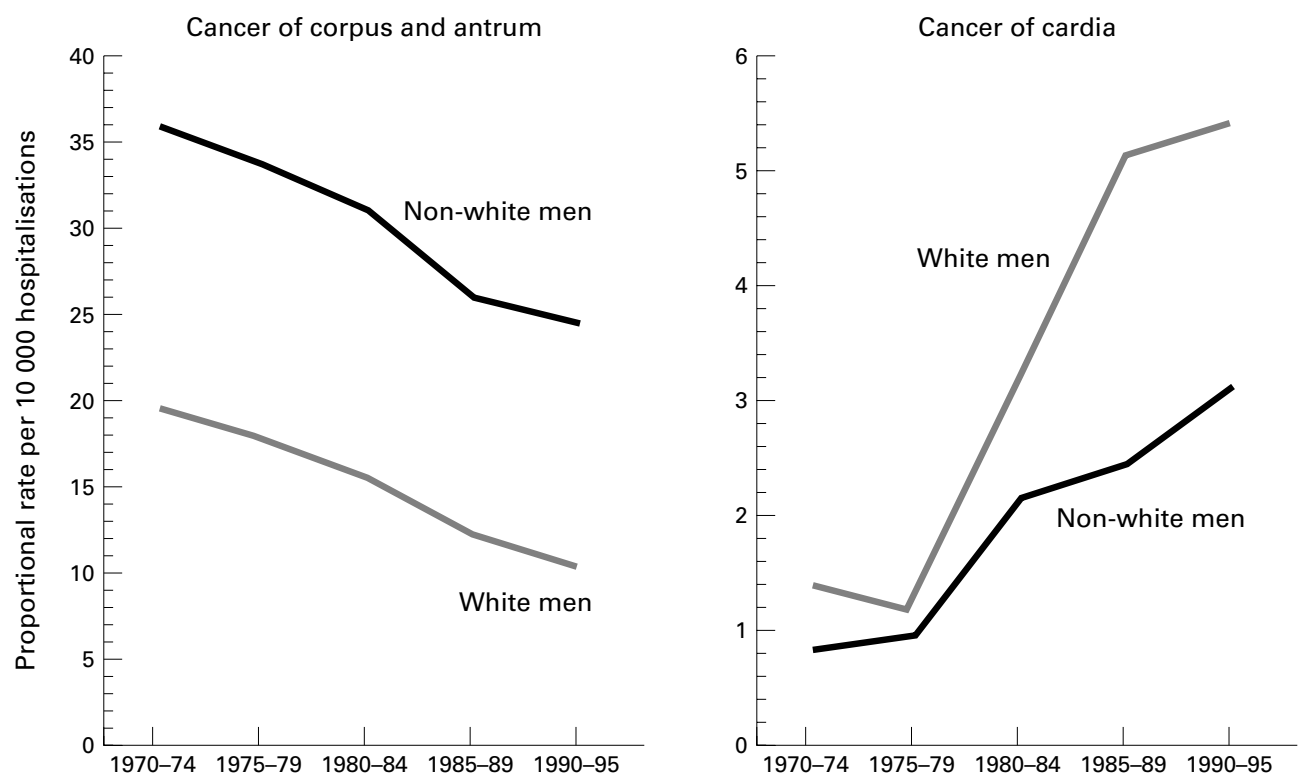

Figure 1 Time trends of hospitalisation for gastric cancer of the corpus or antrum and oesophageal adenocarcinomal cancer of the cardia. Data points represent the average of consecutive time periods as shown on the $x$ axis.

ethnic groups. Cancer of the corpus and antrum was significantly more common among non-white than white subjects (table 2). Oesophageal adenocarcinoma/cancer of the cardia showed exactly the opposite behaviour. It was significantly more common among white than non-white men and showed a significant rise during the same time period (fig 1). It should be noted that the rates of gastric cancer in the corpus and antrum were on the average five times higher than cancer of the cardia.
Both types of peptic ulcer showed a significant decline in their hospitalisation rates between 1970 and 1995, the decline being far more pronounced in duodenal than gastric ulcer (fig 2). In the veterans population, the hospitalisation rates for gastric and duodenal ulcer were similar among whites and nonwhites. In striking contrast with the behaviour of peptic ulcer, the hospital discharges involving GORD rose fourfold and sevenfold among non-whites and whites, respectively, during the
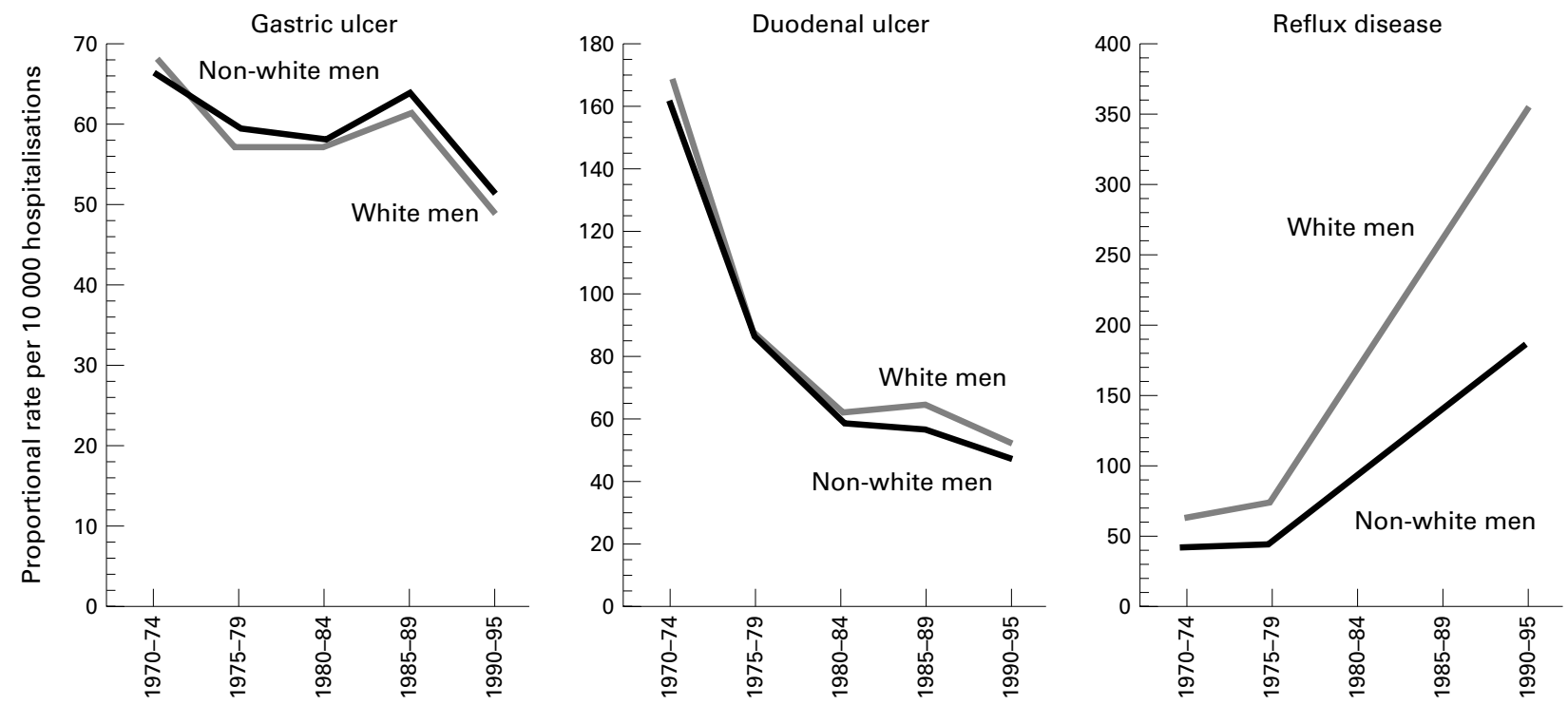

Figure 2 Time trends of hospitalisation for gastric ulcer, duodenal ulcer, and gastro-oesophageal reflux disease. Data points represent the average of consecutive time periods as shown on the $x$ axis. 

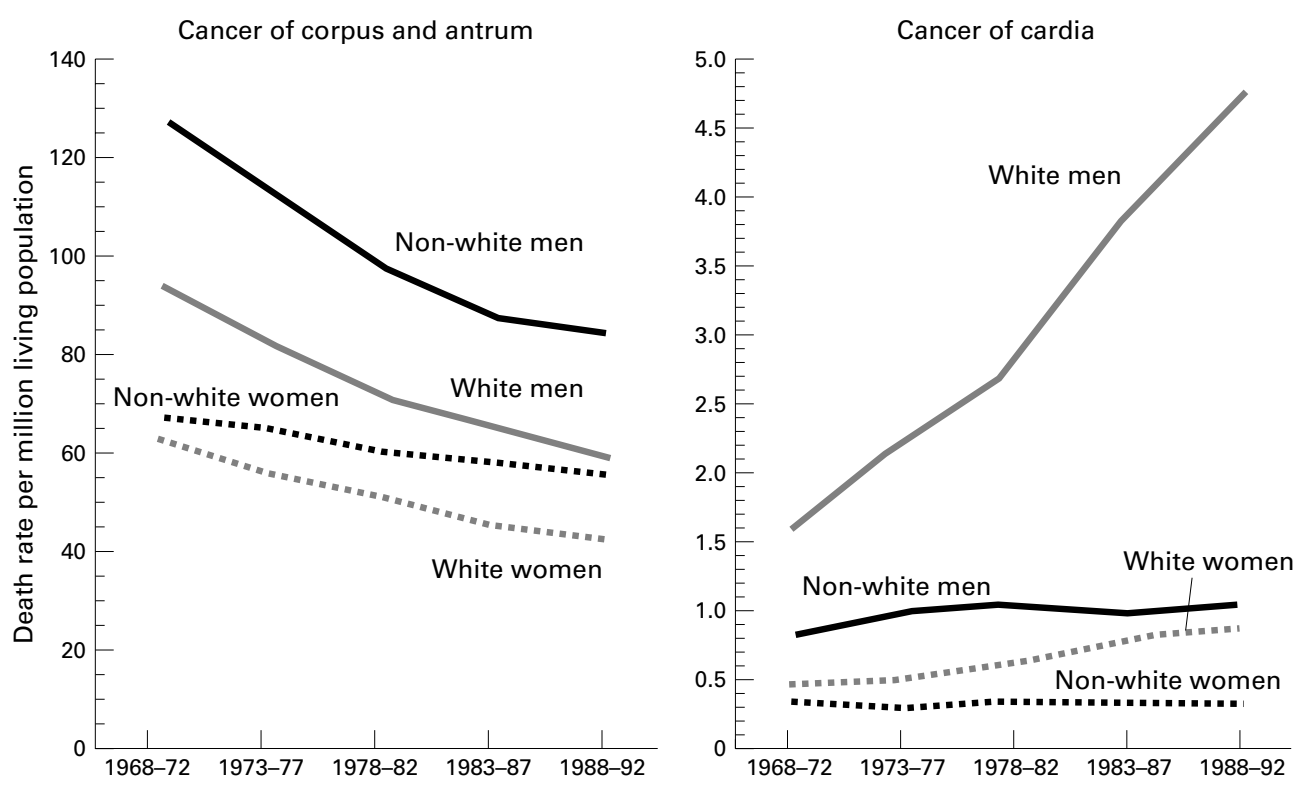

Figure 3 Time trends of death rates from gastric cancer of the corpus or antrum and oesophageal adenocarcinoma/cancer of the cardia. Data points represent the average of consecutive time periods as shown on the $x$ axis.

Table 3 Death rates, US population 1968-1992

\begin{tabular}{lccccc}
\hline Subgroup & Gastric ulcer & Duodenal ulcer & Reflux oesophagitis & Gastric cancer & Cancer of the cardia \\
\hline Men & $12.3(12.2-12.5)$ & $15.3(15.1-15.4)$ & $1.7(1.6-1.8)$ & $77.8(77.4-78.1)$ & $2.9(2.8-2.9)$ \\
Women $_{\text {Whites }}^{\star}$ & $10.3(10.2-10.4)$ & $8.6(8.5-8.7)$ & $1.5(1.4-1.6)$ & $50.2(49.9-50.4)$ & $0.6(0.6-0.6)$ \\
Non-whites & $11.7(11.6-11.8)$ & $12.6(12.5-12.7)$ & $1.7(1.6-1.7)$ & $61.4(61.2-61.6)$ & $1.9(1.9-1.9)$ \\
$1968-1972 \dagger$ & $9.0(8.8-9.2)$ & $7.3(7.1-7.5)$ & $1.1(1.0-1.2)$ & $76.8(76.2-77.4)$ & $0.6(0.6-0.7)$ \\
$1988-1992$ & $7.4(17.1-17.7)$ & $19.6(19.3-19.9)$ & $1.0(1.0-1.1)$ & $78.8(78.3-79.4)$ & $0.9(0.9-1.0)$ \\
\end{tabular}

Rates are expressed per million living population and shown with their $95 \%$ confidence interval.

* Sex and race specific rates represent the average values of the period 1968-1992.

$+1979-1982$ in case of reflux oesophagitis.

same time period. Hospitalisations with GORD were significantly more common among whites than non-whites (table 2).

The time trends of the death rates for cancer and their breakdown by race provide an almost exact replica of the corresponding patterns in the hospitalisation data (fig 3). While cancer of the corpus and antrum declined between 1968 and 1992, oesophageal adenocarcinoma in- creased during the same time period. However, the rise in oesophageal adenocarcinoma was not significant among non-white men. As in the hospitalisation rates, a higher death rate from gastric cancer among non-whites contrasted with a higher death rate from oesophageal adenocarcinoma among whites (table 3). In general, white and non-white women behaved similarly to their male counterparts. Gastric
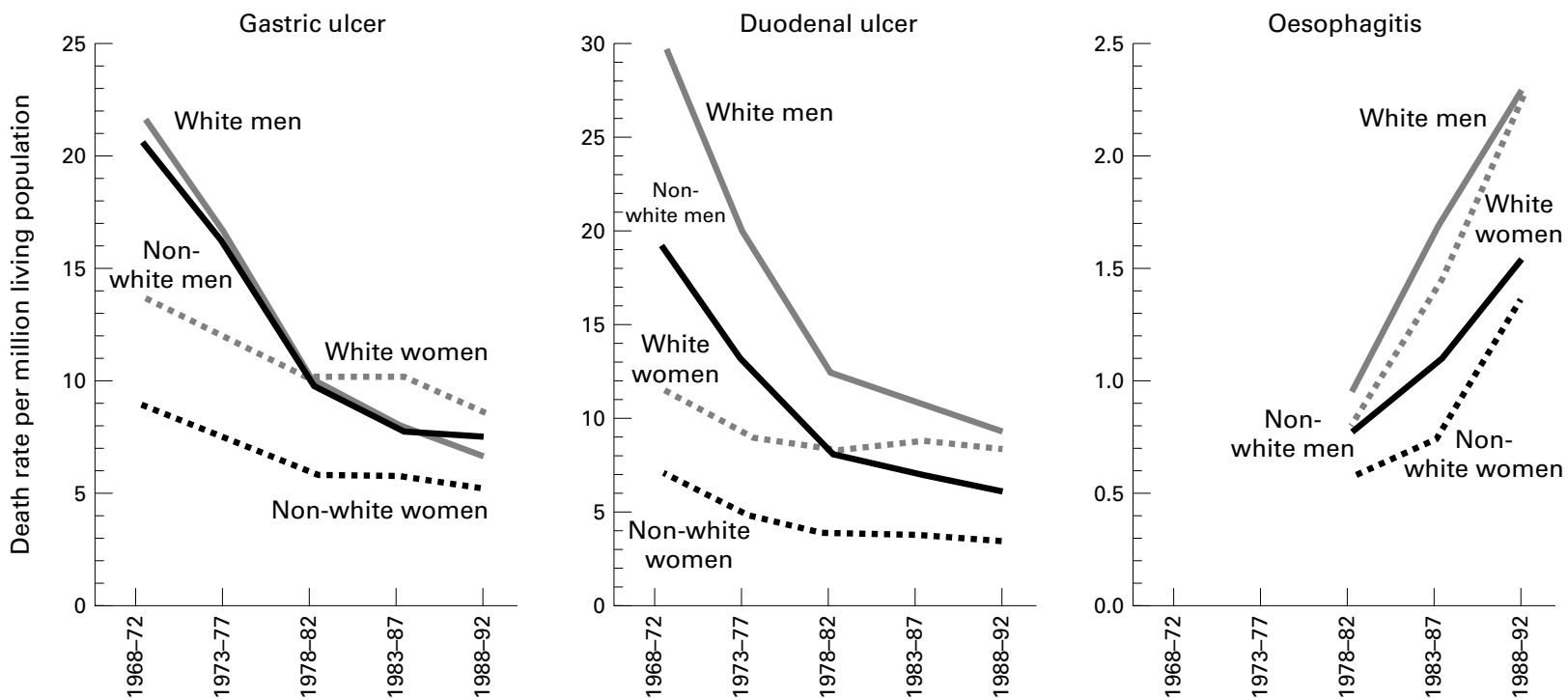

Figure 4 Time trends of death rates from gastric ulcer, duodenal ulcer, and erosive oesophagitis. Data points represent the average of consecutive time periods as shown on the $x$ axis. 
cancer of the corpus and antrum was less common among white than non-white women, while oesophageal adenocarcinoma was more common among white than non-white women. In women from both ethnic groups, gastric cancer of the corpus and antrum decreased, while oesophageal adenocarcinoma increased. However, the decrease and increase in death rates from both cancer types was less pronounced in women than in men.

With regard to the hospitalisation rates shown in fig 2 , both ulcer types were also characterised by a significant decline in their death rates (fig 4). The decline affected white men as well as non-white men (fig 4). The decline in mortality from peptic ulcer was less pronounced among women than men. Despite its relatively infrequent occurrence, death rates from oesophagitis revealed a consistent and significant rise in all sex and race groups. In agreement with the hospitalisation data, the mortality from oesophagitis was significantly more common among whites than non-whites (table 3). The trends of mortality from oesophagitis and its ethnic distribution also matched the patterns observed with respect to oesophageal adenocarcinoma/cancer of the cardia in both data sources.

\section{Discussion}

This study shows two distinct and opposing patterns among diseases affecting the gastroduodenum and the oesophagus. On the one hand, peptic ulcer and gastric cancer have decreased continuously during the past 25 years. On the other hand, GORD and oesophageal adenocarcinoma increased continuously during the same time period. In addition to their opposing temporal trends, these diseases also revealed contrasting patterns with respect to their ethnic distribution. While non-white patients became much less affected with GORD and oesophageal adenocarcinoma, they harboured higher rates of gastric cancer. The two independent databases used to delineate these epidemiological patterns yielded strikingly similar results.

Because $H$ pylori plays an essential role in the pathogenesis of gastric ulcer, duodenal ulcer, and gastric cancer, the general decline in its infection rate in Western societies provides the most likely explanation for the time trends of these three diseases. The acquisition of $H$ pylori results in the development of acute gastritis that, if left untreated, gives way to chronic gastroduodenitis. ${ }^{18-20}$ Both types of peptic ulcer disease are strongly correlated with a gastroduodenal infection by $H$ pylori. ${ }^{5}$ Chronic gastritis that involves large areas of the gastric body (corpus) results in partial atrophy of the acid secreting mucosa and hypochlorhydria. ${ }^{8}{ }^{9}$ The resultant atrophic gastritis and intestinal metaplasia of the infected gastric mucosa also constitute precancerous lesions of the stomach. ${ }^{19-21}$ Several serological and histological studies have shown a strong association between $H$ pylori infection and gastric cancer. ${ }^{34}$ As such a sequence of events progresses slowly over prolonged time periods, it is seen particularly in elderly persons who acquired $H$ pylori infection at an early age.
In addition to being responsible for the time trends of peptic ulcer and gastric cancer, $H$ pylori infection also offers a possible explanation for the trends of GORD and oesophageal adenocarcinoma. The decline in gastric acidity observed with advancing age seems to be related to an $H$ pylori induced atrophy of the gastric mucosa. ${ }^{22}$ Furthermore, a reversal of gastritis associated hypochlorhydria renders individuals more susceptible to reflux of acid and the development of erosive oesophagitis. ${ }^{11}{ }^{11}$ Labenz et al followed patients with duodenal ulcer after antibiotic cure of $H$ pylori infection for three years. ${ }^{11}$ The incidence of reflux oesophagitis was $25.8 \%$ after eradication of $H$ pylori compared with $12.9 \%$ in patients with persistent infection. In a related study, De Koster et al found that patients with endoscopically diagnosed reflux oesophagitis were less likely to have active corpus gastritis than patients without oesophagitis. ${ }^{12}$ Other groups have also observed higher rates of gastric $H$ pylori infection in patients without as compared with patients with severe forms of oesophagitis, characterised by erosions and Barrett's mucosa. $^{23}{ }^{24}$ Barrett's mucosa is a premalignant lesion for oesophageal adenocarcinoma. ${ }^{25}$

A past history of gastric or duodenal ulcer in patients with oesophageal adenocarcinoma or cancer of the gastric corpus and antrum was assessed in a case control study among patients followed at hospitals of the US Department of Veterans Affairs. ${ }^{26}$ A previous history of gastric, but not duodenal ulcer was associated with a significantly elevated risk for subsequently developing cancer of the gastric corpus and antrum. This suggests that gastric ulcer and gastric cancer share a similar set of risk factors, including $H$ pylori. In the same study, gastric ulcers exerted no significant influence on oesophageal adenocarcinoma, while duodenal ulcers and peptic ulcers (site unspecified) were even protective. These latter associations indicate that some patients with gastroduodenal $H$ pylori infection, as evidenced by their previous ulcer history, may be protected against reflux disease and oesophageal adenocarcinoma.

In our study, a complementary piece of evidence to support the role of $H$ pylori in GORD is provided by the obvious differences among ethnic groups. While US non-whites incurred substantially reduced hospitalisations and mortality related to GORD or oesophageal adenocarcinoma, they suffered more from gastric cancer than whites. In general, non-whites in the United States tend to harbour higher rates of infection with $H$ pylori acquired at a younger age than whites. ${ }^{27}$ Again, this pattern translates into prolonged time periods of chronic gastritis and a greater chance of developing gastric atrophy associated with reduced acid output. Gastric atrophy and reduced acid output mean a greater risk for gastric cancer and a smaller risk for GORD and oesophageal adenocarcinoma, respectively.

We utilised two large databases to obtain independent measures of disease frequencythat is, hospitalisation and mortality. The overall size and the make up of the US veterans population, from which the hospitalised 
patients are recruited, are not well characterised. To avoid problems arising from prevalence rates based on inexact population denominators, we calculated age adjusted proportional hospitalisation rates. The medical conditions studied in the present analysis are relatively common among male veterans. The Department of Veterans Affairs is the largest nationwide health care provider in the United States. It has kept its computerised records in a uniform fashion over a prolonged time period. These circumstances offered a unique opportunity to study the time trends with great reliability. The demonstration of opposing times trends within the same population, as well as different rates for whites and non-whites, confers additional internal validity to the results of the study. It makes a systematic error or bias unlikely, as such effects would be expected to result in uniform trends among different subgroups. The similarity between the mortality and hospitalisation data in every important aspect further strengthens the validity of the observed trends.

Neither the hospitalisation data nor the vital statistics contain a breakdown by histological categories according to the International Classification of Diseases for Oncology (ICDO). In both databases, some adenocarcinomas of the oesophagus (151.0) might have been miscoded as cancers of the lower third of the oesophagus (ICD9 codes 150.2 and 150.5) or as gastric cancer not otherwise specified (ICD9 code 151.9). A greater proportion of cardiac cancers might have been coded as unspecified gastric cancers in the past than presently. A more precise coding practice during recent times could have increased the rate of cardiac cancer. The increased precision in classification could have resulted from several factors, such as more frequent usage of gastrointestinal endoscopy, better reporting standards, and increasing awareness among clinicians about the different aetiologies of cardiac and other gastric cancers. As cardiac cancer represents only a small portion of all gastric cancer, even a small amount of misclassification would have affected its time trends.

Some of the temporal changes in the occurrence of the five diseases examined here have been reported in previous studies. This provides external validity to the present results. The time trends of gastric and duodenal ulcer during the past three decades were characterised by a notable decline in their incidence and prevalence rates. This decline occurred similarly in the United States and many European countries. ${ }^{28} 29$ It was observed in various statistics and affected most morbidity parameters of peptic ulcer disease, such as death rates, hospital discharges, physician visits, disability pensions, and frequency of gastric surgeries secondary to peptic ulcer. $^{30-37}$ The incidence and death rates of gastric cancer have also shown a continuous decline since 1930 in the United States, as well as most European countries. ${ }^{38}$ In the United States, the reduction in the incidence of gastric cancer reflected largely a decline in distal (corpus and antrum) lesions. ${ }^{39}$ Conversely, the incidence rates of gastric cancer involving the proxi- mal stomach (cardia) have been rising steeply. ${ }^{40-42}$ Careful examination of these lesions revealed that most cardiac cancers represented adenocarcinoma of mucosa from the distal oesophagus or the gastro-oesophageal junction. ${ }^{43}$ In these studies as well as in the current study, nevertheless, an increased recognition coupled with a more precise classification could have contributed partially to the observed trends concerning cardiac cancer.

In summary, this study shows two opposing time trends. While on the one hand peptic ulcer disease and gastric cancer are declining, GORD and oesophageal adenocarcinoma show a notable increase. Non-whites are less affected by GORD and oesophageal adenocarcinoma. We propose that the general decline in the infection with $H$ pylori represents a potential biological mechanism for these opposing time trends.

1 Sonnenberg A. Temporal trends and geographical variations of peptic ulcer disease. Aliment Pharmacol Ther of peptic ulcer disea

2 Boring CC, Squires TS, Tong T. Cancer statistics, 1992. CA Cancer F Clin 1992;42:19-38.

3 Parsonnet J, Friedman GD, Vandersteen DP, et al. Helicobacter pylori infection and the risk of gastric carcinoma. $N$ Engl F Med 1991;325:1127-31.

4 Forman D, Newell DG, Fullerton F, et al. Association between infection with Helicobacter pylori and risk of gastric cancer: evidence from a prospective investigation. BMF 1991;302:1302-5.

5 Nomura A, Stemmermann GN, Chyou PH, et al. Helicobacter pylori infection and the risk for duodenal and gastric ulceration. Ann Intern Med 1994;120:977-81.

6 Banatvala N, Mayo K, Mégraud F, et al. The cohort effect and Helicobacter pylori. F Infect Dis 1993;168:219-21.

7 Parsonnet J. The incidence of Helicobacter pylori infection. Parsonnet J. The incidence of Helicobacter pylo

8 Sipponen P, Hyvärinen H. Role of Helicobacter pylori in the pathogenen $\mathrm{P}$, Hyvärinen $\mathrm{H}$. Role of Helicobacter pylori in the
pastritis, peptic ulcer and gastric cancer. pathogenesis of gastritis, peptic ulcer and gast

9 Sipponen P, Seppälä K, Äärynen M, et al. Chronic gastritis and gastroduodenal ulcer: a case control study on risk of coexisting duodenal or gastric ulcer in patients with gastritis. Gut 1989;30:922-9.

10 Schütze K, Hentschel E, Dragosics B, et al. Helicobacter pylori reinfection with identical organisms: transmission by the patients' spouses. Gut 1995;36:831-3.

11 Labenz J, Blum AL, Bayerdörffer, et al. Curing Helicobacter pylori infection in patients with duodenal ulcer may
provoke reflux esophagitis. Gastroenterology 1997;112: 1442-7.

12 De Koster E, Fehat M, Deprez C, et al. Helicobacter pylori, gastric histology and gastro-oesophageal reflux disease [abstract]. Gut 1995;37:A36.

13 World Health Organization. The international classification of diseases, 8th revision. Adapted for use in the United States. diseases, 8 th revision. Adapted for use in the United States.
DHHS publication no. (PHS) 1693. Washington, DC: DHHS publication no. (PHS) 1693. Washington, DC:
Public Health Service, US Government Printing Office, Public

14 World Health Organization. The international classification of diseases, 9th revision. Clinical modification, 2nd edn. DHHS Publication No. (PHS) 80-1260. Washington, DC: Public Health Service, US Government Printing Office, September 1980.

15 National Center for Health Statistics. Vital statistics of the United States, 1968-1990, vol II, mortality, part A. Washington, DC: Public Health Service, 1970-1995.

6 Kahn HA, Sempos CT. Statistical methods in epidemiology. New York, NY: Oxford University Press, 1989:87-95.

17 Letner C (ed). Geigy scientific tables. Vol 2. 8th edn. Basle, Switzerland: Ciba-Geigy, 1982:152,224.

18 Kekki M, Sipponen P, Siurala $M$, et al. Peptic ulcer and chronic gastritis: their relation to age and sex, and to locaion of ulcer and gastritis. Gastroenterol Clin Biol 1990;14: $217-23$

19 Lechago J, Correa P. Prolonged achlorhydria and gastric neoplasia: is there a causal relationship? Gastroenterology 1993;104:1551-7.

20 Sipponen P. Long-term consequences of gastroduodenal inflammation. Eur $\mathcal{f}$ Gastroenterol Hepatol 1992;4(suppl 2): $225-9$

21 Kuipers EJ, Uyterlinde AM, Peña AS, et al. Long-term sequelae of Helicobacter pylori gastritis. Lancet 1995;345 1525-8.

22 Katelaris PH, Seow F, Lin BPC, et al. Effect of age, Helicobacter pylori infection and gastritis with atrophy on serum gastrin and gastric acid secretion in healthy men. Gut gastrin and gastric

23 Ohara S, Sekine H, Iijima K, et al. Gastric mucosal atrophy and prevalence of Helicobacter pylori in reflux esophagitis of 
the elderly (in Japanese). Nippon Shokakibyo Gakkai Zasshi (Fapanese Fournal of Gastroenterology) 1996;93:235-9.

24 Blaser MJ Perez-Perez GI, Lindenbaum J, et al Association of infection due to Helicobacter pylori with specific upper gastrointestinal pathology. Rev Infect Dis 1991;13(supp 8):S704-8.

25 Spechler SJ, Goyal RK. Barrett's esophagus. $N$ Engl f Med 1986;315:362-71.

26 Molloy RM, Sonnenberg A. The relationship between gastric cancer and previous peptic ulcer disease. Gut 1997; 40:247-52.

27 Malaty HM, Evans DG, Evans DJ, et al. Helicobacter pylori in Hispanics: comparison with blacks and whites of similar age an

28 Coggon D, Lambert P, Langman MJS. 20 years of hospital admissions for peptic ulcer in England and Wales. Lancet 1981;i:1302-4.

29 Bloom BS, Kroch E. Time trends in peptic ulcer disease and in gastritis and duodenitis. Mortality, utilization and in gastritis and duodenitis. Mortality, utilization and 333-42.

30 Elashoff JD, Grossman MI. Trends in hospital admissions and death rates for peptic ulcer in the United States from 1970 to 1978 . Gastroenterology 1980;78:280-5.

31 Wylie CM. The complex wane of peptic ulcer. I. Recent national trends in deaths and hospital care in the United States. F Clin Gastroenterol 1981;3:327-32.

32 Sonnenberg A. Changes in physician visits for gastric and duodenal ulcer in the united states during 1958-1984 as shown by national disease and therapeutic index (NDTI). Dig Dis Sci 1987;32:1-7.
33 Sonnenberg A. Disability pensions due to peptic ulcer in Germany between 1953 and 1983. Am 7 Epidemiol Germany between

34 Smith MP. Decline in duodenal ulcer surgery. $\mathcal{F} A M A$ 1977; 237:987-8.

35 Fineberg HV, Pearlman LA. Surgical treatment of peptic ulcer in the United States. Trends before and after the introduction of cimetidine. Lancet 1981;i:1305-7.

36 Walker LG. Trends in the surgical management of duodenal ulcer. A fifteen year study. Am $\mathcal{F}$ Surg 1988;155:436-8.

37 Gustavsson S, Kelly KA, Melton III LJ, et al. Trends in peptic ulcer surgery. A population-based study in Rochester, 8 Sandler RS. Gastric cancer. In: JE Everhart, ed. Digestive diseases in the United States: epidemiology and impact. US Department of Health and Human Services. NIH publication No. 94-1447. Washington, DC: US Government Printing Office, 1994:181-204.

39 Fuchs CS, Mayer RJ. Gastric carcinoma. $N$ Engl f Med 1995;333:32-41.

40 Hesketh PJ, Clapp RW, Doos WG, et al. The increasing frequency of adenocarcinoma of the esophagus. Cancer 1989; 64:526-30.

41 Powell J, McConkey CC. Increasing incidence of adenocarcinoma of the gastric cardia and adjacent sites. Br f Cancer 1990;62:440-3

42 Blot J, Devesa SS, Kneller RW, et al. Rising incidence of adenocarcinoma of the esophagus and gastric cardia. fAMA 1991;265:1287-9.

43 Locke III GR, Talley NJ, Carpernter HA, et al. Changes in the site- and histology-specific incidence of gastric cancer during a 50-year period. Gastroenterology 1995;109:1750-6. 